\title{
Daily Profiles of Dehydroepiandrosterone and Its Hydroxylated Metabolites with Respect to Food Intake
}

\author{
Luboslav Stárka, Beata Rácz, Monika Šrámková, Martin Hill, \\ Michaela Dušková \\ Institute of Endocrinology, Prague, Czech Republic \\ Received January 23, 2015; Accepted March 12, 2015.
}

Key words: Daily profile - Dehydroepiandrosterone - 7-hydroxydehydroepiandrosterone - 16-hydroxy-dehydroepiandrosterone - Food intake

Abstract: Eight women of reproductive age with normal body mass index were given 5 standardised meals, and their hormonal milieu was determined during the course of the day. Plasma from 12 withdrawals was analysed for dehydroepiandrosterone and its 7- and 16-hydroxylated metabolites. Overall, there was a maximum in the levels of steroid hormones in the morning, followed by decreases throughout the day. There was also an additional significant decrease found for dehydroepiandrosterone and its $7 \alpha$-hydroxyderivative in association with the consumption of main meals, but not for the $7 \beta$-isomer or 16a-hydroxyderivative.

This study was supported by Internal Grant Agency of the Ministry of Health, Czech Republic - NT-12340.

Mailing Address: Prof. RNDr. Luboslav Stárka, MD., DSc., Institute of Endocrinology, Národní 8, 11694 Prague 1, Czech Republic; e-mail: Istarka@endo.cz 


\section{Introduction}

Dehydroepiandrosterone (DHEA) has long been a well-known steroid, first isolated and identified by Butenandt in 1934 and considered for nearly half a century as a degradation product, though its sulfate (DHEAS) is the most abundant circulating steroid. In addition to being a weak androgen and precursor of testosterone and estrogens, DHEA was reported to have antiglucocorticoid action as well as function as a neuroactive steroid synthesized by certain neurons. It gained intensive interest in the 1990s when Baulieu called it "the hormone of youth" and demonstrated some of its beneficial effects (Baulieu, 1996). Its plasmatic level is reduced with ageing in most individuals, but not all. As shown by correlation studies, lowered levels of DHEA have been linked to a higher death rate (Ohlsson et al., 2015). An improvement in well-being as well as in some mental functions was reported after a $50 \mathrm{mg}$ daily intake of DHEA by many authors. A non-negligible portion of DHEA is hydroxylated at C7 and C16 to $7 \alpha-, 7 \beta-$ and $16 \alpha-$ and $16 \beta$-hydroxyderivatives. At least a part of the antiglucocorticoid function of DHEA has been ascribed to its 7-oxygenated metabolites, namely to $7 \alpha$-hydroxydehydroepiandrosterone. 17 $\alpha$-hydroxy-DHEA was first isolated and identified in normal human urine in 1962 (Stárka et al., 1962), and after 30 years was found to be an important compound in the maintenance of the balance between cortisol and cortisone due to the discovery that the system 7-hydroxy-DHEA - 7-oxo-DHEA competes with the system cortisol-cortisone for the activity of 11ß-hydroxysteroid dehydrogenase (Hennebert et al., 2007a, b). This occurs with various intensities in local tissues, including the brain (Morfin and Stárka, 2001).

DHEA is a neuroactive steroid and exerts its activity on various channels in the brain (Hill et al., 2015; Stárka et al., 2015), and due its anti-glucocorticoid action it is also considered a factor in fat deposition processes (Sedláčková et al., 2012). Thus, we were interested in examining daily profiles of DHEA and its metabolites, as well as possible associations with the daily variation of hormones associated with food intake.

\section{Material and Methods}

Subjects

Eight women were involved in the study. They were $25-35$ years of age with a mean of $29.48 \pm 2.99$ years. Their BMI was normal, with a mean BMI of $21.3 \pm 1.3$. All were premenopausal, non-smokers, healthy and used no medications or hormonal contraception. All subjects were in the follicular phase (1-7 day of menstrual cycle). The volunteers were kept in standardized conditions for five days (8 hours of sleeping and periodic eating according to a standardized menu, which did not markedly differ from their normal daily program habits).

The Ethical Committee of the Institute of Endocrinology in Prague approved the protocol of the study, and written informed consent was obtained from all participants. 
During the trial, all of the volunteers consumed similar food with a standard amount of carbohydrates, proteins and lipids, with a total caloric value of about $8,400 \mathrm{~kJ}$. The participants ate only meals according to the prepared menu and kept a time table. Common physical activity was allowed during the trial. The study lasted 16 hours, from 5:30 a.m. to 9:30 p.m.

Before the first blood sampling the subjects were given an intravenous cannula (in the cubital or forearm vein). The first withdrawals of blood were at 6 a.m. (30 minutes after awaking) after overnight fasting. The next withdrawals were always one and two hours after eating according to the following schedule $\mathbf{7 : 1 5}$, 8:15, 10:15, $11: 15$ a.m.; 1:15, 2:15, 4:15, 5:15, 7:15, 8:15 p.m.). The last blood withdrawals were 30 minutes before sleep, at 9:30 p.m. Breakfast (1 piece of bread, ham, cheese and tea) was served at 6:15, a snack (yogurt) at 9:15, lunch (soup beef broth, turkey, potato dumpling, sauerkraut) at 12:15, another snack (apple) at 15:15 and dinner (tomato, 2 pieces of bread, ham and cheese) at 18:15.

\section{Analytical methods}

Each sample was collected into a cooled plastic tube containing $100 \mu \mathrm{l}$ of $5 \%$ EDTA. The plasma was obtained after centrifugation for $5 \mathrm{~min}$ at $2000 \mathrm{~g}$ at $4{ }^{\circ} \mathrm{C}$. Plasma was separated and frozen within half an hour of being drawn from the subject, and was stored at $-20{ }^{\circ} \mathrm{C}$ until analysed.

C-peptide was measured in serum using ECLIA (electrochemiluminiscence immunoassay, Modular E 170 analyser, Roche). The measuring range of the kit (defined by the lower detection limit and the maximum of the master curve) was $0.003-13.3 \mathrm{nmol} / \mathrm{l}$ or $0.01-40.0 \mathrm{ng} / \mathrm{ml}$ for plasma. Intra- and inter-assay coefficients of variation were $1.5 \%$ and $2.3 \%$, respectively.

Blood glucose was measured using the enzymatic reference method with hexokinase (Cobas Integra 400 plus analyser, Roche). The measuring range of the kit was $0.12-40 \mathrm{mmol} / \mathrm{l}(2.16-720 \mathrm{mg} / \mathrm{dl})$. Intra-set and inter-set reproducibility were $1.7 \%$ and $2.6 \%$, respectively.

Cortisol was determined by the conventional RIA method.

Steroids measured by GCIMS method

The levels of unconjugated steroids and steroid polar conjugates after hydrolysis were concomitantly measured in cubital vein blood using the GC-MS method (Hill et al., 2010).

In brief, free steroids were extracted from plasma by diethyl-ether; steroid conjugates were hydrolysed and extracted. The resulting residues were derivatized by methoxyamine hydrochloride and analysed by GC/MS as follows.

\section{Chemicals and reagents}

Steroids were purchased from Steraloids (Newport, RI, USA), Sylon B from Supelco (Bellefonte, PA, USA), methoxylamine hydrochloride from Sigma (St. Louis, MO, USA), and solvents from Merck (Darmstadt, Germany). 


\section{Instruments}

Measurements of steroid levels were done on a GCMS-QP2010 Plus system by Shimadzu (Kyoto, Japan) consisting of a gas chromatograph equipped with automatic flow control, an AOC-20s autosampler, and a single quadrupole detector with an adjustable electron voltage of 10-195 V.A capillary column with a medium polarity RESTEK Rxi column (diameter $0.25 \mathrm{~mm}$, length $15 \mathrm{~m}$, film thickness $0.1 \mu \mathrm{m}$ ) was used for analyses. Electronimpact ionization with electron voltage fixed at $70 \mathrm{~V}$ and emission current set to $160 \mu \mathrm{A}$ was used. The temperatures of the injection port, ion source and interface were maintained at $220^{\circ} \mathrm{C}, 300^{\circ} \mathrm{C}$, and $310^{\circ} \mathrm{C}$, respectively. Analyses were carried out in the splitless mode with a constant linear velocity of the carrier gas $(\mathrm{He})$, which was maintained at $60 \mathrm{~cm} / \mathrm{s}$. The septum purge flow was set at $3 \mathrm{ml} / \mathrm{min}$. The samples were injected using the high pressure mode $(200 \mathrm{kPa})$, which was maintained for $1 \mathrm{~min}$. The detector voltage was set to $1.4 \mathrm{kV}$.

\section{Statistical data analysis}

The changes of steroid levels were evaluated using a repeated measures ANOVA model consisting of a Subject factor, explaining differences between subjects, and a Stage factor. Due to the non-Gaussian data distribution and non-constant variance, the original data was transformed by a power transformation to attain symmetric distribution of the data and residuals as well as homoscedasticity (Meloun et al., 2000). The homogeneity of the transformed data was checked by residual analysis as described elsewhere (Meloun et al., 2002, 2004).

\section{Results}

C-peptide and glucose showed a pattern dependent on food intake, with a significant maximum 1 an 2 hours after lunch and dinner (Figure $1 \mathrm{~A}$ and $\mathrm{B}$ ),
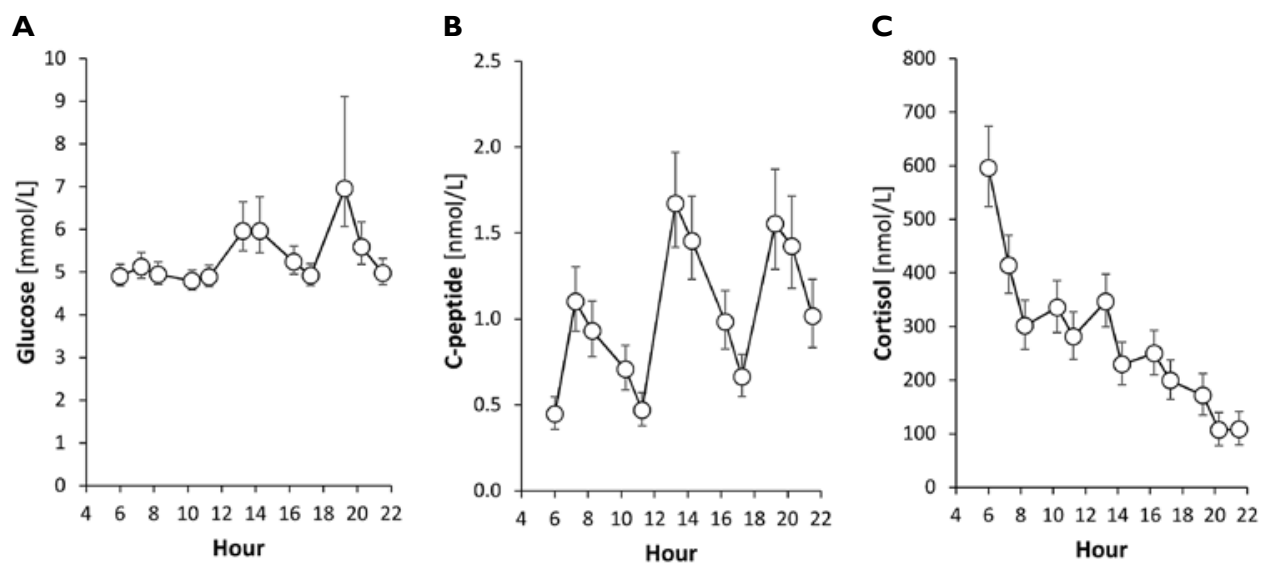

Figure 1 - Daily profile of substances related to food intake:A) glucose; B) C-peptide; C) cortisol. 
A

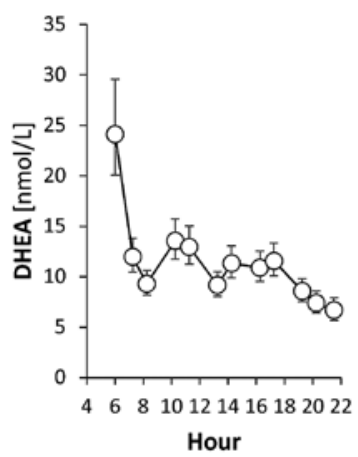

B

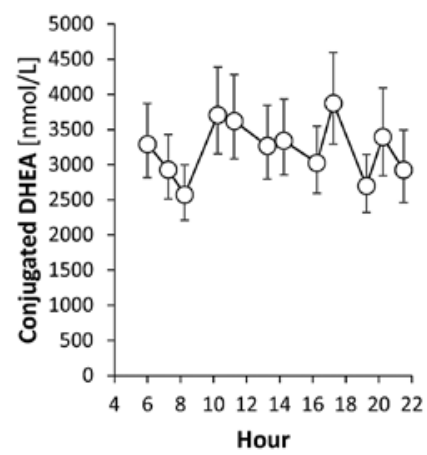

C

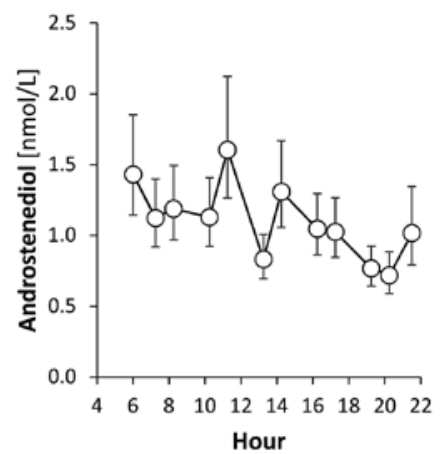

Figure 2 - Daily profile of dehydroepiandrosterone and its metabolites: A) free dehydroepiandrosterone; B) conjugated dehydroepiandrosterone; C) androstenediol.

A

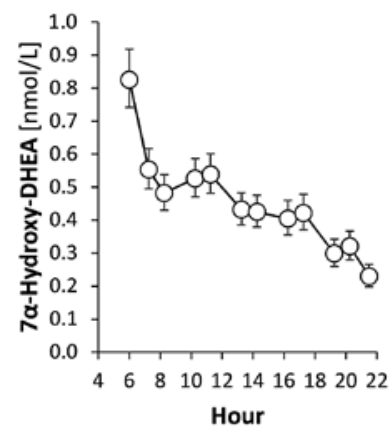

B

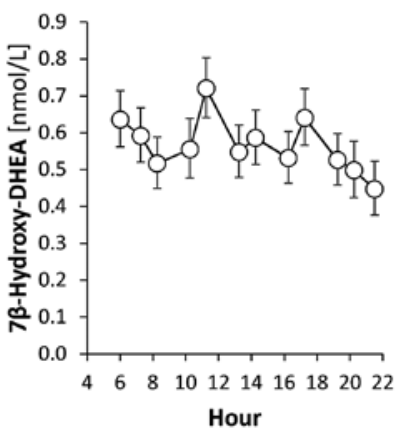

C

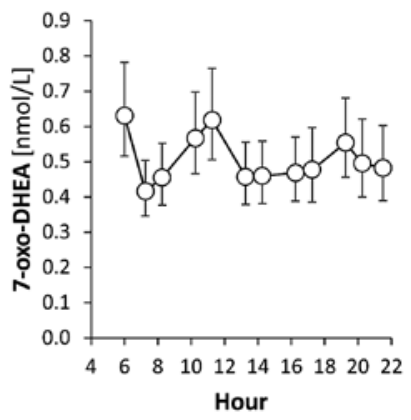

Figure 3 - Daily profile of 7-oxygeneted metabolite of dehydroepiandrosterone:A) 7 $\alpha$-hydroxydehydroepiandrosterone; B) 7 $\beta$-hydroxy-dehydroepiandrosterone; C) 7-oxo-dehydroepiandrosterone.

A

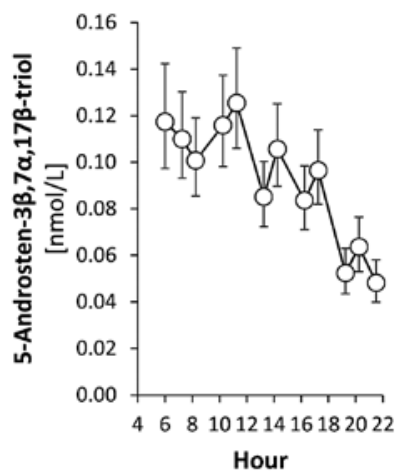

B

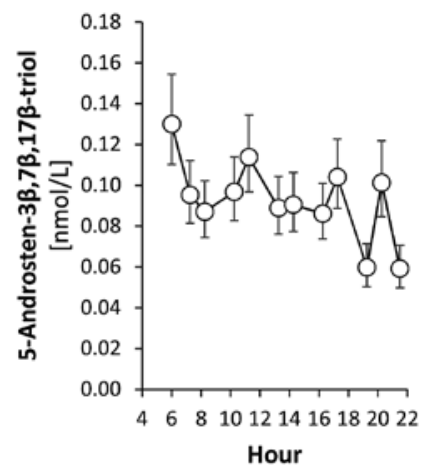

C

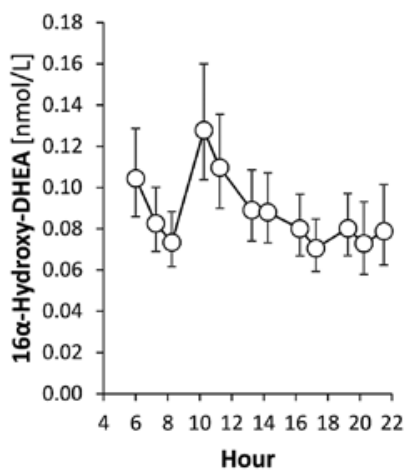

Figure 4 - Daily profile of hydroxylated metabolites of dehydroepiandrosterone:A) 5-androstene-3 $\beta, 7 \alpha, 17 \beta$-triol; B) 5 -androstene-3 $\beta, 7 \beta, 17 \beta$-triol; C) 16 $\alpha$-hydroxy-dehydroepiandrosterone.

Stárka L.; Rácz B.; Šrámková M.; Hill M.; Dušková M. 
Table 1 - Statistical characteristic of diurnal profiles of dehydroepiandrosterone and its metabolites using repeated measures ANOVA with factor Hour and Subject

\begin{tabular}{|c|c|c|c|c|c|}
\hline \multirow[t]{2}{*}{ Steroid } & \multicolumn{2}{|c|}{ Hour } & \multirow[t]{2}{*}{ Steroid } & \multicolumn{2}{|c|}{ Subject } \\
\hline & $\mathrm{H}-\mathrm{F}$ & $\mathrm{P}$ & & S-F & $\mathrm{P}$ \\
\hline $\begin{array}{l}\text { 5-androstene-3beta, } \\
\text { 17beta-diol-C }\end{array}$ & 2.98 & 0.0027 & DHEA-C & 10.2 & $<0.0001$ \\
\hline DHEA-C & 3.76 & 0.0004 & $\begin{array}{l}\text { 5-androstene-3beta, } \\
\text { 17beta-diol }\end{array}$ & 10.3 & $<0.0001$ \\
\hline 7-oxo-DHEA & 3.92 & 0.0003 & $\begin{array}{l}\text { 5-androstene-3beta, } \\
\text { 17beta-diol-C }\end{array}$ & 10.3 & $<0.0001$ \\
\hline $\begin{array}{l}\text { 5-androstene-3beta, } \\
\text { 17beta-diol }\end{array}$ & 4.71 & 0.0000 & 7-oxo-DHEA & 12.3 & $<0.0001$ \\
\hline 16alpha-OH-DHEA & 10.39 & 0.0000 & DHEA & 12.4 & $<0.0001$ \\
\hline DHEA & 11.42 & 0.0000 & 16alpha-OH-DHEA & 34.5 & $<0.0001$ \\
\hline 7beta-OH-DHEA & 14.84 & 0.0000 & 7beta-OH-DHEA & 49.4 & $<0.0001$ \\
\hline $\begin{array}{l}\text { 5-androstene-3beta,7alpha, } \\
\text { 17beta-triol }\end{array}$ & 22.65 & 0.0000 & 7alpha-OH-DHEA & 64.5 & $<0.0001$ \\
\hline $\begin{array}{l}\text { 5-androstene-3beta,7beta, } \\
\text { 17beta-triol }\end{array}$ & 24.43 & 0.0000 & $\begin{array}{l}\text { 5-androstene-3beta, } \\
\text { 7alpha,17beta-triol }\end{array}$ & 67.1 & $<0.0001$ \\
\hline 7alpha-OH-DHEA & 28.95 & 0.0000 & $\begin{array}{l}\text { 5-androstene-3beta, } \\
\text { 7beta,17beta-triol }\end{array}$ & 82.2 & $<0.0001$ \\
\hline 16alpha-OH-DHEA-C & 33.29 & 0.0000 & 16alpha-OH-DHEA-C & 119.5 & $<0.0001$ \\
\hline
\end{tabular}

$\mathrm{H}-\mathrm{F}$ - Hour factor showing the differences between time periods; S-F - Subject factor showing the differences between individual subjects; $\mathrm{P}$ - significance; $\mathrm{C}$ - conjugate

but not 1 or 2 hours after snacks. Cortisol (Figure 1C) had a nearly steady decrease throughout the day, with no significant association with food intake in the intervals 1 or 2 hours after food intake. Free DHEA showed a small but significant decrease after lunch and dinner, whereas conjugated DHEA decreased only after dinner (Figure 2A and B). Androstenediol decreased after lunch, but other changes were not significantly influenced by meals (Figure $2 \mathrm{C}$ ). $7 \alpha$-hydroxydehydroepiandrosterone (Figure $3 \mathrm{~A}$ ) and $3 \beta, 7 \alpha, 17 \beta$-hydroxy-androstenetriol (Figure 4A) followed the profile of DHEA, but $7 \beta$-isomer (Figure 3B), 7-oxoderivative (Figure $3 C$ ) and 3 $3,7 \beta, 17 \beta$-hydoxy-androstenetriol (Figure 4B) did not. DHEA and all its derivatives showed an increase at 10 or 11 a.m., which, however, was significant only for free and conjugated DHEA, 7 $\beta$-hydroxy-DHEA and $16 \alpha$-hydroxy-DHEA (Figure 4C). These increased values were very probably not connected with meal intake, as glucose and C-peptide being not elevated any more one or two hours after the intake of a small snack. 
The results of statistical analysis are given in Table 1, which shows that the interindividual differences in hormone values were high between subjects, but not between hours of blood withdrawal.

\section{Discussion}

DHEA is a prohormone that is secreted by the adrenal cortex on a nyctohemeral rhythm, similar to that of cortisol or testosterone. Cortisol and DHEA-S concentrations reflect the activity of the hypothalamus-pituitary-adrenal (HPA) axis, and both cortisol and DHEA-S have significant awakening responses (Ghiciuc et al., 2011). The diurnal rhythm of DHEA has been studied by several authors (Mikulecky et al., 1995; Ghiciuc et al., 2011; Prom-Wormley et al., 2011; Heaney et al., 2012), mainly with an emphasis on the morning awaking response. However, blood withdrawals during the day were not frequently used in these studies and did not reflect the food intake at all. Here, we tested the daily fluctuations of the metabolites of DHEA for the first time.

The concentration of circulating free DHEA shows a general tendency to decrease from high morning values to a minimum in the afternoon, a daily rhythm that is common to other steroid hormones such as cortisol or testosterone. It might be expected that the metabolites of DHEA would show a similar pattern, but no such significant rhythm was found for conjugated DHEA, conjugated androstenediol, free 7-oxo-DHEA or 16 $\alpha$-hydroxy-DHEA.

Our data show that DHEA, its conjugated form, androstenediol and $7 \alpha$-hydroxydehydroepiandrosterone decrease one or two hours after main meals, i.e. lunch and dinner, whereas the metabolites 7 $\beta$-hydroxy-DHA, 7-oxo-DHEA, 16 $\alpha$-hydroxyDHEA do not significantly fluctuate during the day in relation to food intake.

The physiological role of 7-hydroxy- and 7-oxo-derivatives of DHEA was studied by several authors. It has been shown that $7 \alpha$ - and $7 \beta$-hydroxylated steroids, which are present in the circulation, may serve as locally active immunoprotective agents (Hampl et al., 1997); they are neuroactive steroids (Morfin and Stárka, 2001) and anti-glucocorticoid agents exerting this activity as substrates for

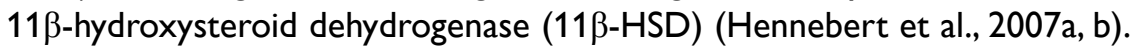
$11 \beta$-HSD is the same enzyme that mediates the interconversion of cortisol and cortisone and 7-hydroxy and 7-oxo derivatives serve as concurrent substrates regulating the local concentration of cortisol. This mechanism could be also the factor modulating the disposition for obesity (Sedláčková et al., 2012; Máčová et al., 2014).

The physiological role of $16 \alpha$-hydroxy-dehydroepiandrosterone (16 $\alpha$-OH-DHEA) is not known (Hampl and Stárka, 2000). 16 $\alpha$-hydroxy-dehydroepiandrosterone sulfate, the major precursor to placental estriol production, has been reported to be lower than normal in hypertensive pregnancies (Warren et al., 1995). Elevated concentration of $16 \alpha$-hydroxy-DHEA has been found in urine from patients with essential hypertension and $16 \alpha-\mathrm{OH}-\mathrm{DHEAS}$, along with estriol sulfate, 
were determined in breast cystic fluid as potential tumour markers (Raju et al., 1989).

The peak in the interval in the late forenoon (10 to $12 \mathrm{~h}$ ) remains to be explained. This peak has also been observed by other authors, e.g. for testosterone by Neaves et al. (1984), where it was more distinct in younger individuals.

\section{Conclusion}

The daily profile of dehydroepiandrosterone levels shows a decrease throughout the day from the highest values in the morning value, with additional significant decreases after main meals. Only some hydroxylated metabolites and conjugated derivatives show a similar profile.

\section{References}

Baulieu, E. E. (1996) Dehydroepiandrosterone (DHEA): a fountain of youth? J. Clin. Endocrinol. Metab. 81(9), 3147-3151.

Ghiciuc, C. M., Cozma-Dima, C. L., Pasquali, V., Renzi, P., Simeoni, S., Lupusoru, C. E., Patacchioli, F. R. (2011) Awakening responses and diurnal fluctuations of salivary cortisol, DHEA-S and $\alpha$-amylase in healthy male subjects. Neuro Endocrinol. Lett. 32(4), 475-480.

Hampl, R., Morfin, R., Stárka, L. (1997) 7-hydroxylated C19-steroids: what are they good for? Endocr. Regul. 31, 211-218.

Hampl, R., Stárka, L. (2000) Minireview: 16 $\alpha$-hydroxylated metabolites of dehydroepiandrosterone and their biological significance. Endocr. Regul. 34(3), 161-163.

Heaney, J. L., Phillips, A. C., Carroll, D. (2012) Ageing, physical function, and the diurnal rhythms of cortisol and dehydroepiandrosterone. Psychoneuroendocrinology 37(3), 341-349.

Hennebert, O., Chalbot, S., Alran, S., Morfin, R. (2007a) Dehydroepiandrosterone 7alpha-hydroxylation in human tissues: Possible interference with type 111 beta-hydroxysteroid dehydrogenase-mediated processes. J. Steroid Biochem. Mol. Biol. 104(3-5), 326-333.

Hennebert, O., Pernelle, C., Ferroud, C., Morfin, R. (2007b) 7alpha- and 7beta-hydroxy-epiandrosterone as substrates and inhibitors for the human 11 beta-hydroxysteroid dehydrogenase type 1. J. Steroid Biochem. Mol. Biol. 105(1-5), 159-165.

Hill, M., Pařízek, A., Cibula, D., Kancheva, R., Jirásek, J. E., Jirkovská, M., Velíková, M., Kubátová, J., Klímková, M., Pašková, A., Žižka, Z., Kancheva, L., Kazihnitková, H., Zamrazilová, L., Stárka, L. (2010) Steroid metabolome in fetal and maternal body fluids in human late pregnancy. J. Steroid Biochem. Mol. Biol. 122, 114-132.

Hill, M., Dušková, M., Stárka, L. (2015) Dehydroepiandrosterone, its metabolites and ion channels. J. Steroid Biochem. Mol. Biol. 145, 293-314.

Máčová, L., Bičíková, M., Zamrazilová, H., Hill, M., Kazihnitková, H., Sedláčková, B., Stárka, L. (2014) Reduced levels of circulating 7alpha-hydroxy-dehydroepiandrosterone in treated adolescent obese patients. Physiol. Res. 63(1), 95-101.

Meloun, M., Hill, M., Militký, J., Kupka, A. K. (2000) Transformation in the PC-aided biochemical data analysis. Clin. Chem. Lab. Med. 38, 553-559.

Meloun, M., Militký, J., Hill, M., Brereton, R. G. (2002) Crucial problems in regression modelling and their solutions. Analyst 127, 433-450.

Meloun, M., Hill, M., Militký, J., Vrbíková, J., Stanická, S., Škrha, J. (2004) New methodology of influential point detection in regression model building for the prediction of metabolic clearance rate of glucose. Clin. Chem. Lab. Med. 42, 311-322. 
Mikulecky, M., Kreze, A., Putz, Z., Moravcik, M. (1995) Daily variation of serum cortisol, 17-hydroxyprogesterone and five androgens in healthy women. Braz. J. Med. Biol. Res. 28(4), 485-490.

Morfin, R., Stárka, L. (2001) Neurosteroid 7-hydroxylation products in the brain. Int. Rev. Neurobiol. 46, 79-95.

Neaves, W. B., Johnson, L., Porter, J. C., Parker, C. R. Jr., Petty, C. S. (1984) Leydig cell numbers, daily sperm production, and serum gonadotropin levels in aging men. J. Clin. Endocrinol. Metab. 59(4), 756-763.

Ohlsson, C., Vandenput, L., Tivesten, $\AA$. (2015) DHEA and mortality: What is the nature of the association? J. Steroid Biochem. Mol. Biol. 145, 248-253.

Prom-Wormley, E. C., York, T. P., Jacobson, K. C., Eaves, L. J., Mendoza, S. P., Hellhammer, D., Maninger, N., Levine, S., Lupien, S., Lyons, M. J., Hauger, R., Xian, H., Franz, C. E., Kremen, W. S. (2011) Genetic and environmental effects on diurnal dehydroepiandrosterone sulfate concentrations in middle-aged men. Psychoneuroendocrinology 36(10), 1441-1452.

Raju, U., Bradlow, H. L., Skidmore, F. D., Levitz, M. (1989) The concentration of 16x-hydroxy androgens in serum and cyst fluid of women with gross cystic disease of the breast. Steroids 54(1), 101-112.

Sedláčková, B., Dušátková, L., Zamrazilová, H., Matucha, P., Bičíková, M., Stárka, L. (2012) 7-oxygenated derivatives of dehydroepiandrosterone and obesity. Prague Med. Rep. 113(2), 147-155.

Stárka, L., Šulcová, J., Šilink, K. (1962) Die Harnausscheidung des 7-Hydroxydehydroepiandrosteronsulfats. Clin. Chim. Acta 7, 309-316.

Stárka, L., Dušková, M., Hill, M. (2015) Dehydroepiandrosterone as a neurosteroid. J. Steroid Biochem. Mol. Biol. 145, 254-260.

Warren, W. B., Gurewitsch, E. D., Goland, R. S. (1995) Corticotropin-releasing hormone and pituitary-adrenal hormones in pregnancies complicated by chronic hypertension. Am. J. Obstet. Gynecol. 172(2 Pt 1), $661-666$. 